\title{
Schizophrenia: illness, stigma and misconceptions
}

\author{
Timothy G Dinan
}

Ir J Psych Med 1999; 16(1): 3-4

Many clinicians will agree that schizophrenia can be the most debilitating of all psychiatric disorders. It usually strikes adolescents and young adults, disrupting their pursuit of educational and occupational goals and drastically reducing their quality of life. Affecting one in every 100 people in Ireland at some point in their lives and with 15 new cases occurring per 100,000 population per annum, it is among the major causes of disability in 18-44 year olds. ${ }^{1}$ No society, race or creed are immune from this condition. Yet few if any medical conditions generate such intense misconceptions.

Schizophrenia is associated with significant stigma and discrimination, which further increases the burden on patients and their families. Individuals with schizophrenia often face social isolation, discrimination in housing, education and employment opportunities, and other forms of prejudice. The stigma often extends to family members and to those who provide healthcare services to patients with the disorder. Relative to acute medical and surgical facilities, the provision of psychiatric care is constantly underfunded.

Why is there such stigma and discrimination attached to a diagnosis of schizophrenia? Abounding misconceptions about the disorder must play a significant role. These misconceptions include the view that people with schizophrenia are usually violent and dangerous, the condition is untreatable, people with schizophrenia are likely to infect others with their madness and people with schizophrenia are lazy or unreliable.

\section{The consequences of stigma}

The label of schizophrenia changes the perception of observers, it reduces social acceptability and it means that sufferers inhabit a different space in public perception from those patients hospitalised with physical conditions. This presents a major obstacle to the presentation, diagnosis and ongoing treatment of the illness.

\section{For the individual}

For the individual, stigma associated with a diagnosis of schizophrenia can mean greater reluctance to accept the diagnosis, or even to conceal it. In the post-psychotic phase of an acute episode it can intensify depressive symptoms and the existential crisis so frequently seen following initial episodes of illness. Individuals may feel a sense of shame, failure or a belief that they do not belong or stick out in public. They may endure jeering or direct prejudice and endure victimisation following discharge from hospital, loss of employment, lack of educational opportunities or

Timothy G Dinan, MD, PhD, DSc, Department of Psychiatry Royal College of Surgeons in Ireland, St. Stephen's Green, Dublin 2, Ireland.

SUBMITTED: FEBRUARY 1999. discrimination when renting. These factors play a role in patients declining hospital admission, resulting in an increased latency between onset of symptoms and initiation of treatment, a factor recognised as associated with poorer outcome. Similar factors may lead the patient to miss appointments or comply with their treatment on an intermittent basis only. In summary, stigma can contribute to a poor prognosis, chronic relapsing illness, failure of rehabilitation, homelessness, unemployment isolation and even suicide.

For the family, they have to overcome their own prejudices. They may deny the diagnosis and they may even reject the treatments offered. They may have to overcome local prejudices and suffer from isolation. Such difficulties often result in the misinterpretation of the patients symptoms, with a subsequent increase in critical comments and general tension in the household. The most common example of this is the interpretation of negative symptoms, especially lack of drive and motivation, as laziness.

\section{The power of the media}

Media clearly exerts great influence over audiences. For many people, the media is a source for the language, concepts and imagery of psychiatry. Within the realms of the media, people with schizophrenia are often not newsworthy unless linked to something negative or they are the basis for sensational headlining and cause for the promotion of stereotypes, public fears, myths and bigotry.

When reporting on schizophrenia, certain sections of the media can sometimes use sensational headlines. This can promote fears and myths which leads to stigma and discrimination, which indirectly can cause untold damage on a personal basis to people with schizophrenia and to their families and friends.

Many popular movies also reinforce the spurious link between mental illness and violence. In these movies, there is no differentiation made between mental illness, psychosis and psychopathy, which are lumped together in an all embracing generic term, 'psycho'.

\section{World Psychiatric Association}

In 1996, the World Psychiatric Association embarked on an international programme to fight the stigma and discrimination associated with schizophrenia. The WPA International Programme is designed to dispel the myths and misunderstandings surrounding schizophrenia. The WPA believe that their programme will fight the prejudice in all walks of life, because that prejudice diminishes the quality of life of people with schizophrenia and their families and prevents them from living and working amongst the general population.

The programme's mission is designed to: increase the awareness and knowledge of the nature of schizophrenia and treatment options; to improve public attitudes both 
about those who have schizophrenia and their families; and to generate action to eliminate discrimination and prejudice. Experts from many countries, non-government organisations, associations of patients and their families, as well as government representatives, developed this programme.

Four committees are involved in this international programme. The Steering Committee oversees the programme under the guidance of Professor Norman Sartorius, president of the WPA. The Committee on the Identification and Treatment of Schizophrenia assembles information on diagnosis and treatment. The Committee on the Reintegration of Patients and their Families into the Community formulates strategies for reintegrating those with schizophrenia into their families and the community. The Committee on Strategies to Reduce Stigma and Schizophrenia produces materials and proposals for fighting discrimination and stigma at a societal level. The Review Committee integrates and streamlines the materials and provides a consistent voice for the programme. ${ }^{2}$

\section{Activities in the Irish psychiatric arena}

A multidisciplinary team of experts under the umbrella of an advisory committee was established in June 1998 to advise on a campaign to heighten public and professional awareness and understanding of schizophrenia. The committee comprises consultant psychiatrists, a family doctor, chief nursing officers from psychiatric hospitals, a social worker, journalists from the national and medical press and representatives from the Mental Health Alliance and from Schizophrenia Ireland.

In September 1998, the Advisory Committee commissioned the most extensive piece of Irish lay public research on schizophrenia conducted to date. A total of 1,200 respondents were surveyed on their awareness of and their attitudes to schizophrenia.

The study was designed to investigate general public attitudes towards schizophrenia. It was conducted between September 10-20, 1998 and based on a nationally representative quota sample of 1,200 adults (aged $15+$ ). The fieldwork took place across 60 sampling points (to provide a high degree of geographical spread) and all interviewing was carried out in the home.

In summary the research found that serious misconceptions abound in the public mind concerning the nature of schizophrenia and its devastating effects on people who have this condition. Most importantly the research found that a majority of the Irish population know little or nothing about schizophrenia and a quarter said that they would fear for their safety if confronted by somebody with the disorder. ${ }^{3}$

These misconceptions contribute substantially to serious stigmatisation of people with schizophrenia, which in many cases provide a major obstacle to their successful reintegration into the community.

\section{Communicating the results}

As a way of informing the public, these results were communicated to Irish journalists at a press briefing held in December 1998, at which a woman with schizophrenia also spoke most poignantly about living with this debilitating disorder. The results have also been sent directly to all consultant psychiatrists, NCHDs in psychiatry, chief nursing officers from psychiatric hospitals and all politicians (TDs, senators and MEPs).

\section{Other activities}

In addition to the consumer research, further research is being conducted amongst consultant psychiatrists on the presence of multidisciplinary teams in Irish psychiatric hospitals. The committee aims to communicate the results of this research to media and key politicians through briefing sessions later in the year. These sessions will consider the existence and extent of multiprofessional terms in the psychiatric healthcare services in Ireland and finding issues with regard to the care of people with schizophrenia.

\section{Next steps}

The Committee has also proposed the compilation of a guide for Irish journalists on reporting of schizophrenia. This guide will explain the complexities of schizophrenia in lay terms and will aim to encourage well-researched, balanced journalism when reporting on such a complex and controversial topic.

It is hoped that the guide will break down some of the damaging stereotypes associated with schizophrenia and will stimulate a more thoughtful approach to the subject by encouraging journalists to always use the correct and accepted terminology and avoid terminology that might create public fear, myth, bigotry and distress to individuals affected by the illness.

The activities outlined above and others to heighten public and professional awareness and understanding of schizophrenia will continue with force and momentum during 1999.

References

1. Murray CJL, Lopez AD. The Global Burden of Disease. Geneva: WHO; 1996: 270

2. www.openthedoors.com

3. General public attitudes towards schizophrenia. A barometer study commissioned by Eli Lilly, September 1998. 


\section{ABBREVIATED PRESCRIBING INFORMATION: PROVIGILQ}

Please refer to summary of product characteristics before prescribing.

Presentation: White to off-white tablets each containing modafinil $100 \mathrm{mg}$. Indication: Narcolepsy. Dosage: Adults: $200-400 \mathrm{mg}$ daily either as two divided doses in the morning and at noon or as a single morning dose according to response. Elderly: Treatment should start at $100 \mathrm{mg}$ daily which may be increased subsequently to the maximum adult daily dose in the absence of renal or hepatic impairment. Severe renal or hepatic impairment: Reduce dose by half (100-200 mg daily). Children: Not recommended. Contra-indications: Pregnancy, lactation, hypersensitivity to modafinil or any excipients used in Provigil. Warnings and precautions: Patients with major anxiety should only receive Provigil treatment in a specialist unit. Patients should be advised to notify their physician if they become or intend to become pregnant during therapy. Blood pressure and heart rate should be monitored in hypertensive patients. Provigil is not recommended in patients with a history of left ventricular hypertrophy or ischaemic ECG changes, chest pain, arrhythmia or other clinically significant manifestations of mitral valve prolapse in association with CNS stimulant use. Studies of modafinil have demonstrated a low potential for dependence although the possibility of this occurring with long-term use cannot be entirely excluded. Drug interactions: Induction of cytochrome P- 450 isoenzymes has been observed in vitro.
Effectiveness of oral contraceptives may be impaired. When these are used for contraception, a product containing at least $50 \mathrm{mcg}$ ethinyloestradiol should be taken. Tricyclic antidepressants - no clinically relevant interaction was seen in a single dose interaction study of Provigil and clomipramine. However, patients receiving such medication should be carefully monitored. Care should be observed with co-administration of anticonvulsant drugs. Side effects: Nervousness, excitation, aggressive tendencies, insomnia, anorexia, headache, CNS stimulation, abdominal pain, dry mouth, palpitation, tachycardia and tremor have been reported. Nausea and gastric discomfort may occur and may improve when tablets are taken with meals. Pruritic skin rashes have been observed occasionally. Buccofacial dyskinesia has been reported very rarely. Marketing authorisation number: PA $827 / 1 / 1$. Marketing authorisation holder: Cephalon UK Ltd., 11/13 Frederick Sanger Road, Surrey Research Park, Guildford, Surrey GU2 5YD, UK. Legal category: POM. Date of preparation: July 1998. Provigil and Cephalon are registered trademarks.

References: 1. Mitler MM. Sleep 1994; 17: S103-S106. 2. Data on file, Cephalon [676] 3. Lin JS et al. Proc Natl Acad Sci USA 1996; 93 (24): 14128-14133. 4. Simon P et al. Eur Neuropsychopharmacol 1995; 5: 509-514.

Medical Information Department Freefone no. $\quad$ Cephololl

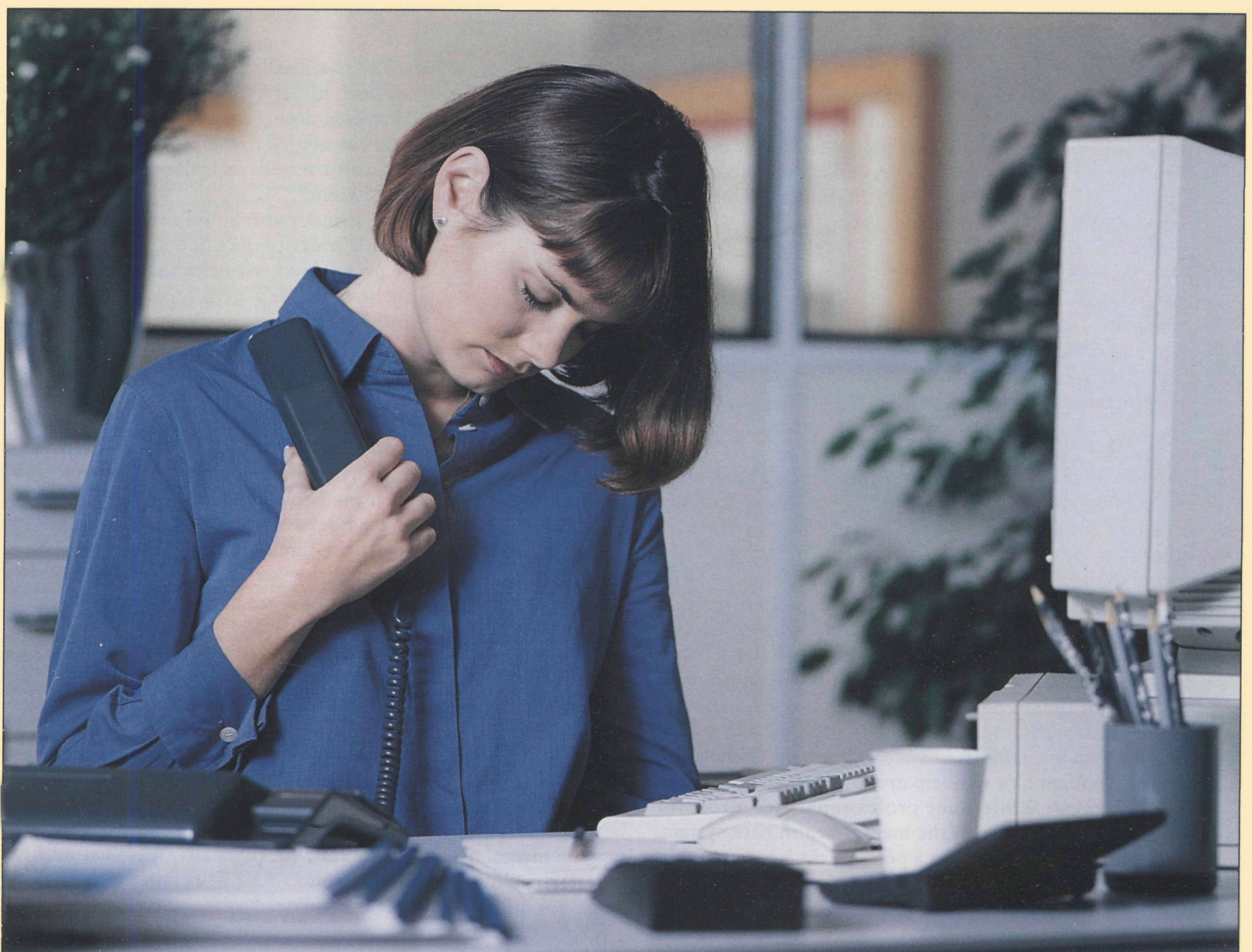

\section{WAKE UP LITTLE SUZIE, WAKE UP}

Excessive sleepiness associated with narcolepsy frequently has a disastrous effect on patients' lives, by impairing their physical, social and emotional well being. Unfortunately, treatment with amphetamines is often associated with a high incidence of unpleasant side effects, which limit their overall benefit.'

Now Provigil (modafinil) - a novel wake promoting agent - offers new advantages in narcolepsy. The clinical efficacy of Provigil has been demonstrated in large controlled clinical studies. In one study, ${ }^{2}$ one in five people with severe narcolepsy reached normal levels of daytime wakefulness while receiving Provigil.

Provigil activates the CNS in a more selective manner than amphetamine and related agents $^{3}$ and differs greatly from this group of drugs in its pharmacology. ${ }^{4}$

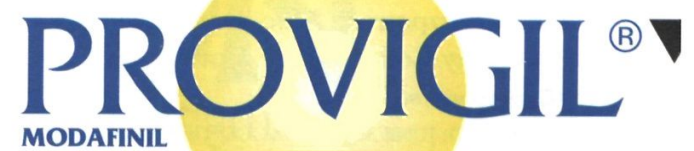

MODAFINIL

A NOVEL, NON AMPHETAMINE WAKE PROMOTING AGENT 